\title{
In Memoriam Albert Sjoerdsma
}

Neuropsychopharmacology (20I5) 40, 306I; doi:I0.I038/npp.20I5.303

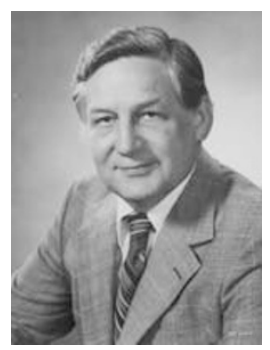

Dr Albert Sjoerdsma died at his North Carolina home on 27 February 2014 of cardiac arrest after an extended illness. He was 89. Born on 28 August 1924, in Lansing, IL, and raised on a truck farm, Dr Sjoerdsma received a doctorate in pharmacology (1948) and a medical degree (1949) from the University of Chicago. Commissioned in the U.S. Public Health Service from 1951 until 1971, he established the Experimental Therapeutics Branch of the National Heart Institute, retiring with the rank of captain (Medical Director).

Dr Sjoerdsma's pioneering work with biogenic amines, initially in collaboration with the laboratories of Dr Sidney Udenfriend, led to the elucidation of serotonin's metabolic degradation to 5-HIAA, discovery of the malignant carcinoid syndrome, elaboration of the clinical and biochemical manifestations of pheochromocytoma, and identification of the mechanism of action of monoamine oxidase inhibitors in humans. His focus on the role of biochemical research in modern drug discovery and development earned him the moniker of 'The Father of Clinical Pharmacology.' Among his therapeutic achievements at the NIH, Dr Sjoerdsma discovered alpha-methyldopa (Aldomet), a breakthrough antihypertensive drug that is still available today. He trained and mentored a generation of clinical pharmacologists, who started academic departments and became known for their own research. I (WML) recall the many hours in Dr Sjoerdsma's office brainstorming about the various research projects ongoing in the lab as the most productive and exciting of my career.
After leaving the NIH to open a new research center in Strasbourg, France, for Richardson-Merrell, Dr Sjoerdsma rose in Merrell's ranks until he became president of the Merrell Dow Research Institute in Cincinnati, with oversight for drug research worldwide. $\mathrm{He}$ was responsible for development of the first-ever non-sedating antihistamine Seldane, whose well-known OTC metabolite Allegra is widely available; the antiepileptic Sabril; and Ornidyl, the first curative drug for West African tryopanosomiasis, which is licensed to the World Health Organization. His daughter Ann Sjoerdsma chronicled his life story and the history of his medical times in her book, 'Starting with Serotonin: How a High-Rolling Father of Drug Discovery Repeatedly Beat the Odds' (2009).

Highly competitive, as well as creative, Dr Sjoerdsma was well known for another compelling interest: shooting craps. During ACNP meetings, he often could be found evenings at the craps table in the Caribe Hilton casino, applying his winning formula. His spirited play would usually attract a crowd of players and onlookers at the table, and he was a favorite of the croupiers. Dr Sjoerdsma liked to take risks and to beat the odds in life and in research. One of his favorite principles was what he called 'The Probability of the Improbable.' Dr Sjoerdsma believed in and bet on the improbable.

Dr Sjoerdsma is survived by his wife of 63 years, Dr Fern MacAllister of Southern Shores, NC; daughters, Leslie (Mark) Swink of Jacksonville, FL; Ann of Southern Shores, NC; and Britt Sjoerdsma of Sarasota, FL; son, Albert Sjoerdsma Jr of Ann Arbor, MI; a brother, and two grandchildren. A memorial service was held in September in Kitty Hawk, NC.

We are honored to have known and worked with Dr Sjoerdsma, an outstanding scientist and clinician, and a maverick in research, who was our good friend.

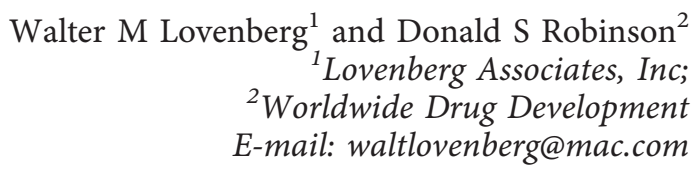

